\title{
Outcomes of erythropoiesis-stimulating agents in cancer patients with chemotherapy-induced anemia
}

\author{
Chris L. Pashos $\cdot$ Kay Larholt • Kimberly A. Fraser • \\ R. Scott McKenzie • Mekré Senbetta • \\ Catherine Tak Piech
}

Received: 4 October 2010 / Accepted: 27 December 2010 /Published online: 27 February 2011

(C) The Author(s) 2011. This article is published with open access at Springerlink.com

\begin{abstract}
Purpose To assess the clinical and economic outcomes among patients with chemotherapy-induced anemia (CIA) treated with United States Food and Drug Administrationapproved fixed dosing regimens of erythropoiesisstimulating agents (ESA).

Methods Data were employed from the Dosing and Outcomes Study of Erythropoiesis-Stimulating Therapies (DOSE) registry to evaluate CIA patients who were initiated on either epoetin alfa (EPO) 40,000 Units (U) or darbepoetin alfa (DARB) 500 micrograms (mcg) between January 1, 2006 and May 8, 2009. Study measurements included ESA treatment dose and dose ratio, changes in hemoglobin $(\mathrm{Hb})$ levels from baseline, and cumulative ESA costs.

Results Five hundred forty patients treated in 44 clinical centers were evaluated, of which 420 were initiated on EPO $40,000 \mathrm{U}$ and 120 were initiated on DARB $500 \mathrm{mcg}$. Both cohorts had similar baseline characteristics, although EPO patients were less likely than DARB patients to have received iron supplementation before ESA initiation (11.4\% EPO vs. $20.0 \%$ DARB, $p=0.015$ ). The EPO-to-DARB dose ratio based on cumulative ESA dose was 169:1 (U EPO: mcg DARB). EPO patients showed statistically greater $\mathrm{Hb}$
\end{abstract}

C. L. Pashos $(\bowtie) \cdot$ K. A. Fraser

United BioSource Corporation,

430 Bedford Street,

Lexington, MA 02420, USA

e-mail: chris.pashos@unitedbiosource.com

K. Larholt

Abt Bio-Pharma Solutions, Inc.,

Lexington, MA, USA

R. S. McKenzie $\cdot$ M. Senbetta $\cdot$ C. T. Piech

Centocor Ortho Biotech Services, LLC,

Horsham, PA, USA improvement compared to DARB patients, and compared to EPO patients, a greater proportion of DARB patients required a blood transfusion $(13.9 \%$ EPO vs. $22.5 \%$ DARB, $p=0.026$ ). Mean cumulative ESA cost was significantly lower for EPO patients than DARB patients $(\$ 4,261$ EPO vs. $\$ 8,643$ DARB, $p<0.0001$ ).

Conclusions These findings reported that patients with CIA achieved more favorable clinical and economic outcomes if initiated with EPO 40,000 U vs. DARB $500 \mathrm{mcg}$.

Keywords Chemotherapy-induced anemia - Erythropoiesisstimulating agents $\cdot$ Clinical outcomes $\cdot$ Healthcare costs

\section{Introduction}

Two erythropoiesis-stimulating agents (ESAs) have been approved by the United States Food and Drug Administration (FDA) for the treatment of chemotherapy-induced anemia (CIA) among cancer patients with non-myeloid malignancies: epoetin alfa (EPO) and darbepoetin alfa (DARB). For patients with CIA and hemoglobin levels below $10 \mathrm{~g} / \mathrm{dL}$, the FDA has approved the treatment of EPO at 40,000 Units (U) per week or $150 \mathrm{U}$ per kg three times weekly and DARB at 500 micrograms $(\mathrm{mcg})$ every 3 weeks or $2.25 \mathrm{mcg}$ per $\mathrm{kg}$ weekly $[1,2]$. Guidelines recommend ESAs for transfusion reduction in CIA, and clinical trials have shown that both EPO and DARB are effective for reducing the need for blood transfusions among CIA patients [1-7]. The resource use and costs associated with ESA treatments have been reported previously [8-11]. Multiple claims-based studies have reported relative ESA utilization with some claims-based studies reporting cumulative utilization and associated cost $[9,10]$. Other such studies have imputed missing ESA data based 
on regression analysis with comparative weekly costs based on various treatment duration methodologies [8, 11]. Additionally, such studies are limited by the lack of clinical data and the assumption of comparable clinical outcomes.

Thus, the objective of this study was to evaluate the clinical and economic outcomes associated with FDAapproved fixed initial ESA doses among CIA patients in actual clinical practice. This is the first national, prospective, observational study to examine the outcomes of patients who initiated ESA treatment with either EPO 40,000 U or DARB $500 \mathrm{mcg}$. The knowledge gained from this study may help inform healthcare providers and payers about the health and economic outcomes associated with these dosing regimens and patterns of care in the real world.

\section{Methods}

\section{Data source}

The Dosing and Outcomes Study of ErythropoiesisStimulating Therapies (DOSE) is a prospective, observational, multi-center registry that collected data on CIA patients treated with ESAs between December 2003 and May 2009 [12]. This analysis employed data from the DOSE registry to evaluate the clinical and economic outcomes of CIA patients initiated on FDA-approved fixed doses of EPO or DARB. Specific data obtained from this registry include baseline demographic and clinical characteristics, ESA utilization, and anemia-related outcomes (e.g., transfusions).

\section{Study population}

As of May 2009, the DOSE registry contained data on 2,349 adult cancer patients (aged $\geq 18$ years) receiving EPO or DARB who had not been treated with either agent within the previous 90 days prior to enrolling in the registry. Patients were excluded from the registry if they were on dialysis for end-stage renal disease, had a diagnosis of myelodysplasia, or were scheduled for stem cell transplantation. Data collection began with the initiation of ESA therapy and continued for either the duration of ESA administration or 16 weeks, whichever was shorter.

The current analysis involved CIA patients initiated between January 1, 2006 and May 8, 2009 on the FDAapproved dosing of EPO 40,000 U or DARB $500 \mathrm{mcg}$. This timeframe was chosen to capture patients affected by the FDA approval of the DARB $500 \mathrm{mcg}$ dosing regimen in March 2006. Patients administered both EPO and DARB during the study period were excluded from the analysis. Patients were also excluded from the analysis if they had less than two EPO or two DARB doses or did not have at least one hemoglobin $(\mathrm{Hb})$ value measured before and at least one after initiation of EPO or DARB. Eligible patients had at least one transfusion-independent $\mathrm{Hb}$ determination (defined as a determination occurring $\geq 28$ days after a transfusion) occurring during the duration of ESA treatment (Fig. 1).

Measurements and analyses

Patients were categorized according to initiated ESA dosing (EPO 40,000 U and DARB $500 \mathrm{mcg}$ ). All patients were assessed at baseline as to demographic characteristics (e.g., age, weight, and gender), cancer type, cancer treatment, and anemia characteristics (e.g., Hb level and iron supplementation).

Actual utilization of EPO and DARB was evaluated during the follow-up period with respect to administered dose per injection, number of days between injections, dose frequency, cumulative ESA dose, treatment duration, number of $\mathrm{Hb}$ determinations, number of office visits, and cumulative ESA cost (based on the cumulative ESA dose and May 2009 wholesale acquisition costs of $\$ 0.014$ per U for EPO and \$4.94 per mcg for DARB). The EPO-toDARB dose ratio (U EPO:mcg DARB) was calculated based on mean cumulative EPO dose divided by the mean cumulative DARB dose. The current analysis included realworld clinical and hematological outcomes measured during the therapeutic duration, defined as the patientspecific ESA treatment duration (the time from first to last ESA dose) plus the patient-specific mean time between all ESA doses. The clinical outcomes reported during the therapeutic duration included the percentage of patients requiring blood transfusion and the number of units of packed red blood cells transfused per study patient. Consistent with analyses of clinical studies in this area, transfusion utilization was measured after day 28 following ESA initiation to allow time for the ESA treatment to be effective [7, 13]. Changes in $\mathrm{Hb}$ levels over baseline were determined at ESA treatment weeks $4,8,12$, and 16 . To account for the potential impact of transfusions on $\mathrm{Hb}$ levels, only transfusion-independent $\mathrm{Hb}$ measures (defined as those occurring $\geq 28$ days after a transfusion) were analyzed.

Data were summarized by descriptive statistics (means, standard deviations, counts, and percentages) and compared using Kruskal-Wallis and chi-square tests for continuous and categorical variables, respectively. Statistical tests were twotailed. All statistical analyses were conducted using SAS version 9.1 [14].

\section{Results}

Baseline characteristics

The current analysis included 540 patients treated in 44 clinical centers, of whom 420 were initiated on EPO 


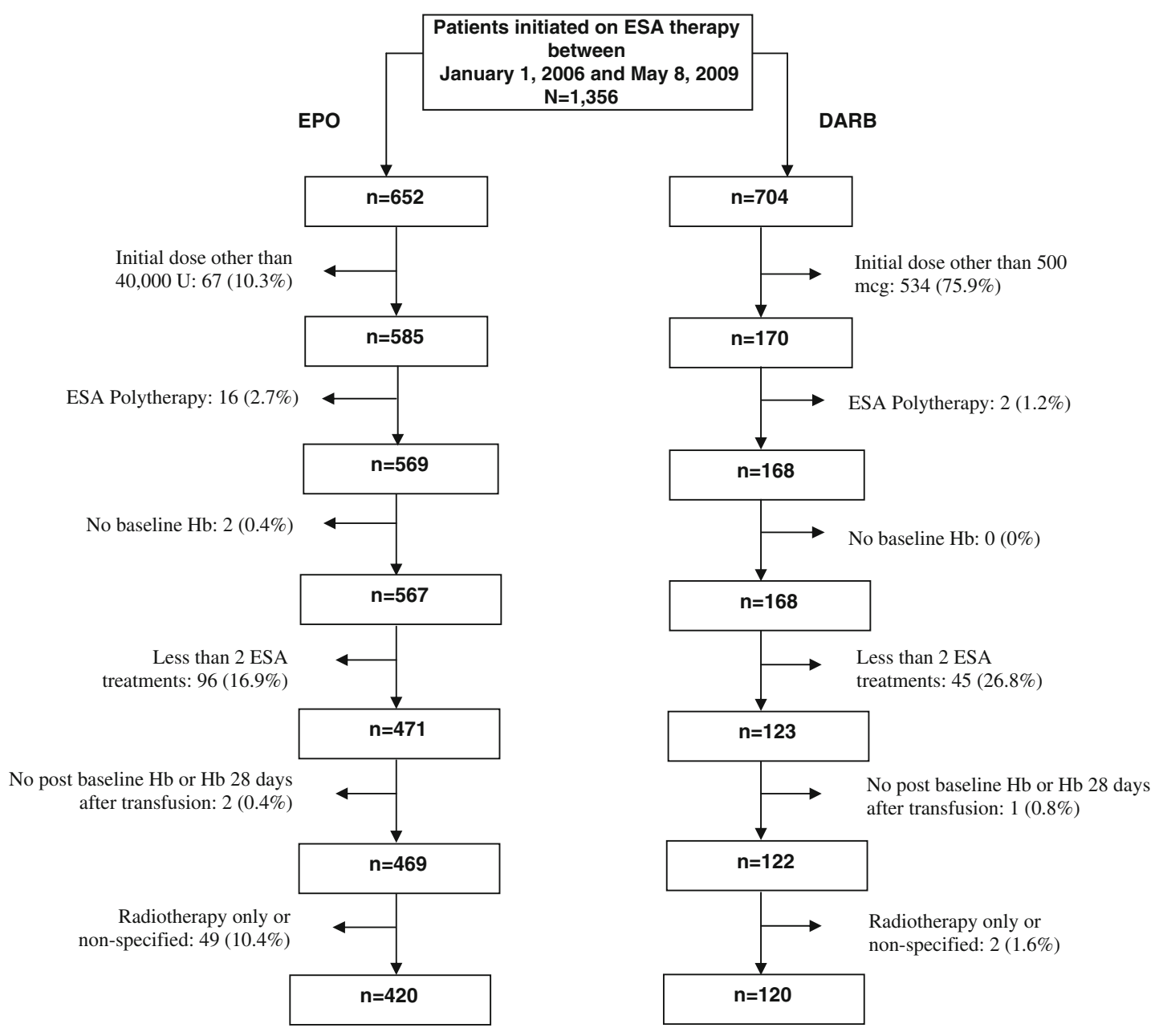

Fig. 1 Patient disposition-EPO 40,000 U or DARB 500 mcg. U Units, $m c g$ micrograms, ESA erythropeiesis-stimulating agent, $H b$ hemoglobin, $E P O$ epoetin alfa, $D A R B$ darbepoetin alfa

40,000 U and 120 were initiated on DARB $500 \mathrm{mcg}$ (Fig. 1). Observed baseline characteristics were similar between the EPO and DARB cohorts except for iron supplementation (Table 1). Mean patient age at treatment initiation was approximately 64 years, and more than $60 \%$ of patients were female. Mean patient weight was close to $75 \mathrm{~kg}$, and mean baseline $\mathrm{Hb}$ level approximated $10 \mathrm{~g} / \mathrm{dL}$. Breast and lung cancer were the most commonly reported cancer types. Most patients were undergoing chemotherapy-only regimens with a similar distribution of platinum and non-platinum-based chemotherapy. Only $3 \%$ of patients had a transfusion within 28 days of initiating an ESA, and a significantly lower proportion of EPO patients had received iron supplementation (11.4\% EPO vs. $20.0 \%$ DARB, $p=0.015)$.

ESA dose and treatment patterns

On average, treatment duration was similar between cohorts (60.9 days EPO, 61.8 days DARB; $p=0.888$ ). The mean administered EPO dose per injection was 41,979 $\mathrm{U}$ and
DARB dose was $488 \mathrm{mcg}$. The mean cumulative ESA dose was 295,058 $\mathrm{U}$ and $1,750 \mathrm{mcg}$ for EPO and DARB patients, respectively, resulting in an EPO-to-DARB dose ratio of 169:1 (U EPO:mcg DARB). Compared to patients initiated on DARB, those initiated on EPO had a significantly higher number of $\mathrm{Hb}$ determinations during treatment (7.7 EPO vs. 5.9 DARB, $p<0.001$ ); however, DARB patients experienced a significantly higher number of office visits during ESA treatment (6.7 EPO vs. 8.1 DARB, $p=0.005$ ) (Table 2).

\section{Clinical and economic outcomes}

Patients administered EPO experienced more favorable changes in $\mathrm{Hb}$ from baseline (Fig. 2) compared to those administered DARB. Increases in $\mathrm{Hb}$ levels from baseline were consistently higher in the EPO group compared to the DARB group through week 12, with statistical significance at weeks $4(0.6 \mathrm{~g} / \mathrm{dL}$ EPO vs. $-0.1 \mathrm{~g} / \mathrm{dL}$ DARB, $p<0.001)$ and 12 (0.6 g/dL EPO vs. 0.1 g/dL DARB, $p=0.032)$. 
Table 1 Baseline characteristics among patients initiated with EPO $40,000 \mathrm{U}$ or DARB $500 \mathrm{mcg}$

$\mathrm{Hb}$ hemoglobin, $E P O$ epoetin alfa, $D A R B$ darbepoetin alfa, ESA erythropoiesis-stimulating agent, $S D$ standard deviation

\begin{tabular}{llll}
\hline Baseline characteristics & EPO & DARB & $P$-value \\
\hline Number of patients & 420 & 120 & \\
Mean age, years (SD) & $63.5(12.4)$ & $64.3(12.6)$ & 0.532 \\
Female gender, $n$ (\%) & $253(60.2)$ & $78(65.0)$ & 0.345 \\
Mean weight, kg (SD) & $74.5(17.5)$ & $77.6(19.9)$ & 0.210 \\
Mean baseline Hb, g/dL (SD) & $10.3(0.89)$ & $10.1(0.96)$ & 0.215 \\
Distribution of primary cancer, $n(\%)$ & & & 0.136 \\
Breast & $85(20.2)$ & $20(16.7)$ & \\
Lung & $114(27.1)$ & $36(30.0)$ & $14(11.7)$ \\
Gastrointestinal & $74(17.6)$ & $7(5.8)$ & \\
Hematologic & $37(8.8)$ & $43(35.8)$ & \\
Other/not specified & $110(26.2)$ & & \\
Therapeutic treatment, $n$ (\%) & & $18(15.0)$ & \\
Radiation and chemotherapy & $46(11.0)$ & $54(45.0)$ & \\
Platinum-based chemotherapy & $189(45.0)$ & $48(40.0)$ & 0.015 \\
Non-platinum-based chemotherapy & $185(44.0)$ & $24(20.0)$ & 0.563 \\
Receiving iron supplementation, $n(\%)$ & $48(11.4)$ & $4(3.3)$ & \\
Had a transfusion 28 days before initiating ESA, $n(\%)$ & $10(2.4)$ & & \\
\hline
\end{tabular}

The proportion of patients requiring a transfusion between day 28 to end of study was significantly lower in the EPO-treated group when compared to the DARB-treated group (13.9\% EPO vs. $22.5 \%$ DARB, $p=0.026)$. Similarly, blood utilization was lower in the EPO- vs. DARB-treated patients (number of units transfused/study patient: $0.4 \mathrm{EPO}$ vs. 0.7 DARB, $p=0.020$ ). The mean number of units transfused per transfused patient was similar for both ESA cohorts (Table 3).

The mean cumulative ESA cost was significantly lower in patients treated with EPO than in patients treated with DARB (\$4,261 EPO vs. \$8,643 DARB, $p<0.0001)$ (Fig. 3).

\section{Discussion}

This analysis employed data from the DOSE registry, a prospective, observational study of actual clinical practice and associated clinical and economic outcomes. This study provides evidence that clinical outcomes associated with ESA initiation of EPO 40,000 U or DARB $500 \mathrm{mcg}$ are consistent with data from previous randomized clinical trials [7, 13]. Moreover, as observed in other studies, this study indicates that ESA costs with EPO are substantially lower per treatment episode than those involving treatment with DARB [9-11].

Table 2 Treatment patterns among patients initiated with EPO 40,000 U or DARB $500 \mathrm{mcg}$

\begin{tabular}{|c|c|c|c|}
\hline & EPO & DARB & $P$-value \\
\hline Mean administered dose per injection, (SD) & 41,979 U $(5,772)$ & $488 \mathrm{mcg}(100)$ & NA \\
\hline Days between injections, mean (SD) & $12.0(8.7)$ & $26.6(14.9)$ & NA \\
\hline Overall dose frequency, $n(\%)$ & & & NA \\
\hline QW & $209(49.8)$ & $0(0.0)$ & \\
\hline Q2W & $161(38.3)$ & $8(6.7)$ & \\
\hline Q3W & $50(11.9)$ & $112(93.3)$ & \\
\hline Mean cumulative ESA dose, (SD) & $295,058 \mathrm{U}(192,387)$ & $1,750 \mathrm{mcg}(870)$ & NA \\
\hline Mean ESA treatment duration, days (SD) & $60.9(35.1)$ & $61.8(32.3)$ & 0.888 \\
\hline Mean (SD) number of $\mathrm{Hb}$ determinations during treatment duration & $7.7(4.9)$ & $5.9(4.1)$ & $<0.001$ \\
\hline Mean (SD) number of office visits during treatment duration & $6.7(6.4)$ & $8.1(6.6)$ & 0.005 \\
\hline
\end{tabular}

$E P O$ epoetin alfa, $D A R B$ darbepoetin alfa, $E S A$ erythropoiesis-stimulating agent, $S D$ standard deviation, $Q W$ once per week, $Q 2 W$ once every two weeks, $Q 3 W$ once every three weeks 
Table 3 PRBC transfusions among patients initiated with EPO 40,000 U or DARB $500 \mathrm{mcg}$

\begin{tabular}{|c|c|c|c|}
\hline & EPO & DARB & $P$-value \\
\hline Day 28 to EOS, $n^{\mathrm{a}}$ & 360 & 120 & \\
\hline Patients requiring PRBC transfusions, $n(\%)$ & $50(13.9)$ & $27(22.5)$ & 0.026 \\
\hline Mean (SD) number of units transfused per transfused patient & $2.7(1.68)$ & $3(1.45)$ & 0.223 \\
\hline Mean (SD) number of units transfused per study patient & $0.4(1.12)$ & $0.7(1.42)$ & 0.020 \\
\hline
\end{tabular}

$E P O$ epoetin alfa, $D A R B$ darbepoetin alfa, $P R B C$ packed red blood cells, EOS end of study, $S D$ standard deviation

${ }^{a}$ Patients with available data from day 28 to EOS were reported in this table

Transfusion reduction is the primary goal of ESA therapy in treating cancer patients with CIA. In this realworld assessment, patients initiated with EPO 40,000 U had lower transfusion rates and greater early $\mathrm{Hb}$ increases compared to patients initiated with DARB $500 \mathrm{mcg}$. These findings are consistent with a previously reported randomized controlled trial of EPO 40,000 U weekly vs. DARB $200 \mathrm{mcg}$ every 2 weeks, which found that EPO-treated patients had significantly greater increases in weekly $\mathrm{Hb}$ from week 3 to study end, as well as lower rates of transfusions and fewer units transfused than DARB-treated patients [15]. In the current study, $13.9 \%$ of EPO-treated patients were transfused, a result similar to a randomized controlled clinical trial that reported blood transfusion in approximately $11 \%$ of patients treated with EPO 40,000 U weekly [13]. Similarly, the current study reported transfusions in $22.5 \%$ of the DARB-treated patients, consistent with the $23 \%$ of patients requiring transfusion in the pivotal clinical study of patients initiated with DARB $500 \mathrm{mcg}$ [7].

The ESA dosing patterns, treatment duration, and dose ratio results from this analysis were similar to other published observational studies. Extended dosing administration has previously been reported [8-12]. Dosing once every 3 weeks with DARB 500 mcg was approved by the FDA in March 2006, during the data collection period of the DOSE registry, and the DARB patients in this study reflect this administration. Furthermore, the dose ratio reported in this study is comparable to other studies using similar methodologies

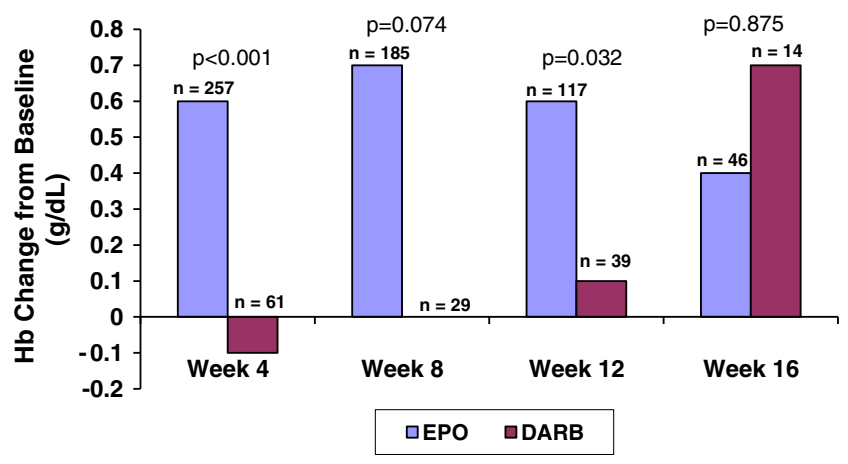

Fig. 2 Mean hemoglobin $(\mathrm{Hb})$ change from baseline among patients initiated with EPO 40,000 U or DARB $500 \mathrm{mcg}$ (i.e., comparison of cumulative dose) in peer-reviewed publications $[9,10]$. Higher dose ratios have been reported with arbitrary extensions of treatment duration for calculation of weekly ESA dose and dose ratio [8, 11]; however, datadriven analyses of actual ESA administration have provided a more complete understanding of the dose ratio $[9,10]$.

This study is the first to report ESA use and costs, using absolute quantities of ESA administered, based on a national, prospective, and observational study of actual care in clinical settings. The finding that CIA patients who initiated with EPO 40,000 U vs. DARB $500 \mathrm{mcg}$ had significantly lower drug costs is noteworthy. Although different methodological approaches have been used to examine the cost of care per treatment episode, this study of real-world treatment patterns supports prior retrospective claims analyses, one of which showed that EPO treatment had a $29 \%$ lower cost of care per treatment episode compared to DARB treatment [9] and another that demonstrated a DARB price premium of $52 \%$ [10]. The current finding that EPO costs were 51\% less than DARB costs may be attributable to the greater precision obtained in this prospective assessment. For this analysis, ESA dose was obtained at every administration to generate a total dose per patient and consequently a mean administered cumulative dose. A budget impact analysis (BIA) of patients initiated on EPO 40,000 U or DARB $500 \mathrm{mcg}$ reported similar ESA drug costs based on a frequencyadjusted DARB dose with a mean administered EPO dose

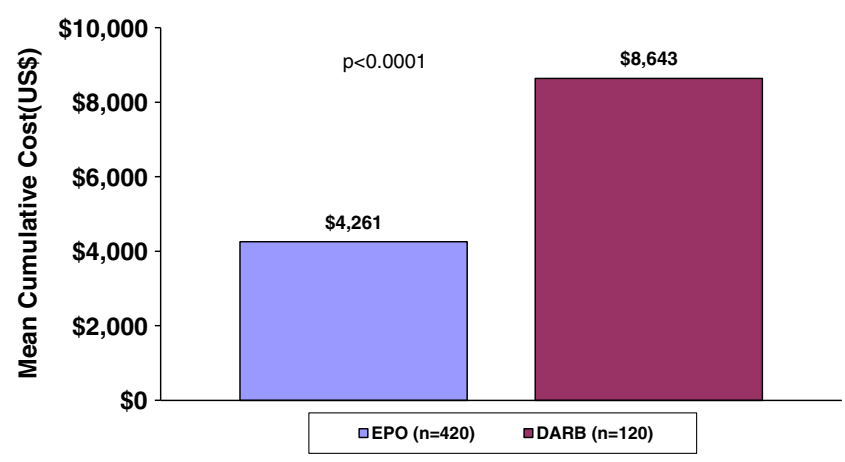

Fig. 3 Mean cumulative ESA cost among patients initiated with EPO $40,000 \mathrm{U}$ or DARB $500 \mathrm{mcg}$ 
(without frequency adjustment) as a base case [16]. The frequency-adjusted DARB dose in the BIA was $375.6 \mathrm{mcg}$ which contrasts with mean administered DARB dose of $487.6 \mathrm{mcg}$ in the present study and could account for differing cost evaluations.

Although the design of the DOSE registry has facilitated the report of a national, real-world comparison between EPO and DARB, several limitations are acknowledged. First, this analysis reflects the results from patients initiated on specific fixed-dose regimens. With heterogeneity of clinical practice, these patients represent a subset of the total population. Interestingly, as shown in Fig. 1, compared to the EPO cohort, a larger proportion of the registry DARB patients were excluded from this analysis because they were not initiated on the FDA-approved fixed dosing regimen. Future analyses will assess the variation of clinical practice and its association with outcomes.

Another area of uncertainty arises from the assessment of patients receiving iron supplementation before ESA initiation. Results show that more DARB patients received iron therapy, and it is possible that this difference may have been associated with hematologic outcomes during the follow-up period. Further research is necessary to examine these differences in iron utilization at baseline and the potential impact on hematologic outcomes and costs.

This analysis focused on a high visibility cost componentcost of ESAs. Although modest differences in healthcare utilization are reported in this study, costs have not been ascribed to them. EPO patients had more $\mathrm{Hb}$ determinations during treatment duration but fewer office visits than DARB patients; however, the magnitude of the utilization differences suggest that the overall cost difference between patients treated with EPO and those treated with DARB are not appreciably affected by these differences. Because the DOSE registry did not collect detailed data on the reason for each office visit, which may have included visits for chemotherapy or other adjuvant therapy, an explanation for these differences is not readily available. Nevertheless, it is conceivable that the greater number of office visits among DARB patients may translate into higher costs among that cohort. Thus, reporting only drug costs may underestimate the total healthcare cost differences between the cohorts.

\section{Conclusion}

Among ESA-treated cancer patients with CIA, this analysis provided a prospective, real-world comparison of dosing in patients initiated with EPO 40,000 U vs. DARB $500 \mathrm{mcg}$. Compared to DARB patients, EPO patients had greater $\mathrm{Hb}$ improvements consistently throughout treatment and a lower proportion of EPO patients underwent transfusions. The dose ratio of 169:1 (U EPO:mcg DARB) was similar to previously published results. The cumulative ESA cost of EPO was $51 \%$ less when compared to DARB. Further research is warranted to extend this analysis to those patients receiving ESA regimens other than those presented here.

Acknowledgments The authors extend their appreciation to the many physicians, nurses, and coordinators at the clinical centers participating in the DOSE registry and to the patients whose care and outcomes we have documented. We also thank Tanya Burton, Neal Mantick, Liz Donahue, Elizabeth Apgar, Lorie Ellis, and others who have helped to ensure the successful conduct of this study and the resulting analysis.

Conflict of interest CLP, KL, and KAF were employees of Abt BioPharma Solutions, Inc., which received research funding by Centocor Ortho Biotech Services, LLC to perform this study. RSM, MS, and CTP are employees of Centocor Ortho Biotech Services, LLC, which sponsored this research. All authors had full control of all primary data and agree to allow the journal to review the data if requested.

Open Access This article is distributed under the terms of the Creative Commons Attribution Noncommercial License which permits any noncommercial use, distribution, and reproduction in any medium, provided the original author(s) and source are credited.

\section{References}

1. PROCRIT ${ }^{\circledR}$ (epoetin alfa) Full Prescribing Information (2010) Distributed by Centocor Ortho Biotech Products, LP. Raritan, NJ

2. Aranesp ${ }^{\circledR}$ (darbepoetin alfa) Full Prescribing Information (2010) Distributed by Amgen, Inc. Thousand Oaks, CA

3. Rizzo JD, Lichtin AE, Woolf SH, Seidenfeld J, Bennett CL, Cella D, Djulbegovic B, Goode MJ, Jakubowski AA, Lee SJ, Miller CB, Rarick MU, Regan DH, Browman GP, Gordon MS (2002) Use of epoetin in patients with cancer: evidence-based clinical practice guidelines of the American Society of Clinical Oncology and the American Society of Hematology. J Clin Oncol 20:4083-4107

4. National Comprehensive Cancer Network. cancer and chemotherapy-induced anemia: version 2.2010 [online]. available from URL: http://www.nccn.org/professionals/physician_gls/ PDF/anemia.pdf [Accessed 2010 March 15]

5. Witzig TE, Silberstein PT, Loprinzi CL, Sloan JA, Novotny PJ, Mailliard JA, Rowland KM, Alberts SR, Krook JE, Levitt R, Morton RF (2005) Phase III, randomized, double-blind study of epoetin alfa compared with placebo in anemic patients receiving chemotherapy. J Clin Oncol 23:2606-2617, Epub 2004 Sep 27

6. Glaspy J, Vadhan-Raj S, Patel R, Bosserman L, Hu E, Lloyd RE, Boccia RV, Tomita D, Rossi G (2006) Randomized comparison of every-2-week darbepoetin alfa and weekly epoetin alfa for the treatment of chemotherapy-induced anemia: the 20030125 study group trial. J Clin Oncol 24:2290-2297

7. Canon JL, Vansteenkiste J, Bodoky G, Mateos MV, Bastit L, Ferreira I, Rossi G, Amado RG, Aranesp 20030231 Study Group (2006) Randomized, double-blind, active-controlled trial of every3 -week darbepoetin alfa for the treatment of chemotherapyinduced anemia. J Natl Cancer Inst 98:273-284 
8. Berger A, Edelsberg J, Kallich J, Oster G (2008) Use of darbepoetin alfa and epoetin alfa in clinical practice in patients with cancer-related anemia. Clin Ther 30:206-218

9. Vekeman F, McKenzie RS, Bookhart BK, Laliberté F, Duh MS, Tak Piech C, Lefebvre P (2009) Drug utilisation and cost considerations of erythropoiesis stimulating agents in oncology patients receiving chemotherapy: observations from a large managed-care database. J Med Econ 12:1-8

10. Lefebvre P, Gosselin A, McKenzie RS, Mody SH, Piech CT, Duh MS (2006) Dosing patterns, treatment costs, and frequency of physician visits in adults with cancer receiving erythropoietic agents in managed care organizations. Curr Med Res Opin 22:1623-1631

11. Daniel G, Hurley D, Whyte JL, Willey V, Wilson M, Kallich J (2009) Use and cost of erythropoiesis-stimulating agents in patients with cancer. Curr Med Res Opin 25:1775-1784

12. Larholt K, Pashos CL, Wang Q, Bookhart B, McKenzie RS, Piech CT (2008) Dosing and outcomes study of erythropoiesisstimulating therapies (DOSE): a registry for characterizing anaemia management and outcomes in oncology patients. Clin Drug Investig 28:159-167

13. Henry DH, Gordan LN, Charu V, Wilhelm FE, Williams D, Xie J, Woodman RC (2006) Randomized, open-label comparison of epoetin alfa extended dosing (80000 U Q2W) vs weekly dosing (40 $000 \mathrm{U} \mathrm{QW}$ ) in patients with chemotherapy-induced anemia. Curr Med Res Opin 22:1403-1413

14. SAS Institute Inc., Cary, NC, USA

15. Waltzman R, Croot C, Justice GR, Fesen MR, Charu V, Williams D (2005) Randomized comparison of epoetin alfa (40, $000 \mathrm{U}$ weekly) and darbepoetin alfa $(200 \mu \mathrm{g}$ every 2 weeks) in anemic patients with cancer receiving chemotherapy. Oncologist 10:642-650

16. Rubin RJ, Glaspy JA, Adams JL, Mafilios MS, Wang SM, Viswanathan HN, Kallich JD (2008) Budget impact analysis of darbepoetin alfa every 3 weeks versus epoetin alfa every week for the treatment of chemotherapy-induced anemia from a US payer's perspective. J Med Econ 11:199-213 